\title{
Using memories to support the self in Alzheimer's disease
}

Article

Accepted Version

Creative Commons: Attribution-Noncommercial-No Derivative Works 4.0

Rathbone, C. J., Ellis, J. A., Ahmed, S., Moulin, C. J. A., Ernst, A. and Butler, C. R. (2019) Using memories to support the self in Alzheimer's disease. Cortex, 121. pp. 332-346. ISSN 19738102 doi: https://doi.org/10.1016/j.cortex.2019.09.007 Available at https://centaur.reading.ac.uk/87303/

It is advisable to refer to the publisher's version if you intend to cite from the work. See Guidance on citing.

To link to this article DOI: http://dx.doi.org/10.1016/j.cortex.2019.09.007

Publisher: Elsevier

All outputs in CentAUR are protected by Intellectual Property Rights law, including copyright law. Copyright and IPR is retained by the creators or other copyright holders. Terms and conditions for use of this material are defined in the End User Agreement.

\section{www.reading.ac.uk/centaur}

\section{CentAUR}

Central Archive at the University of Reading

Reading's research outputs online 


\section{Cortex}

\section{Using memories to support the self in Alzheimer's disease --Manuscript Draft--}

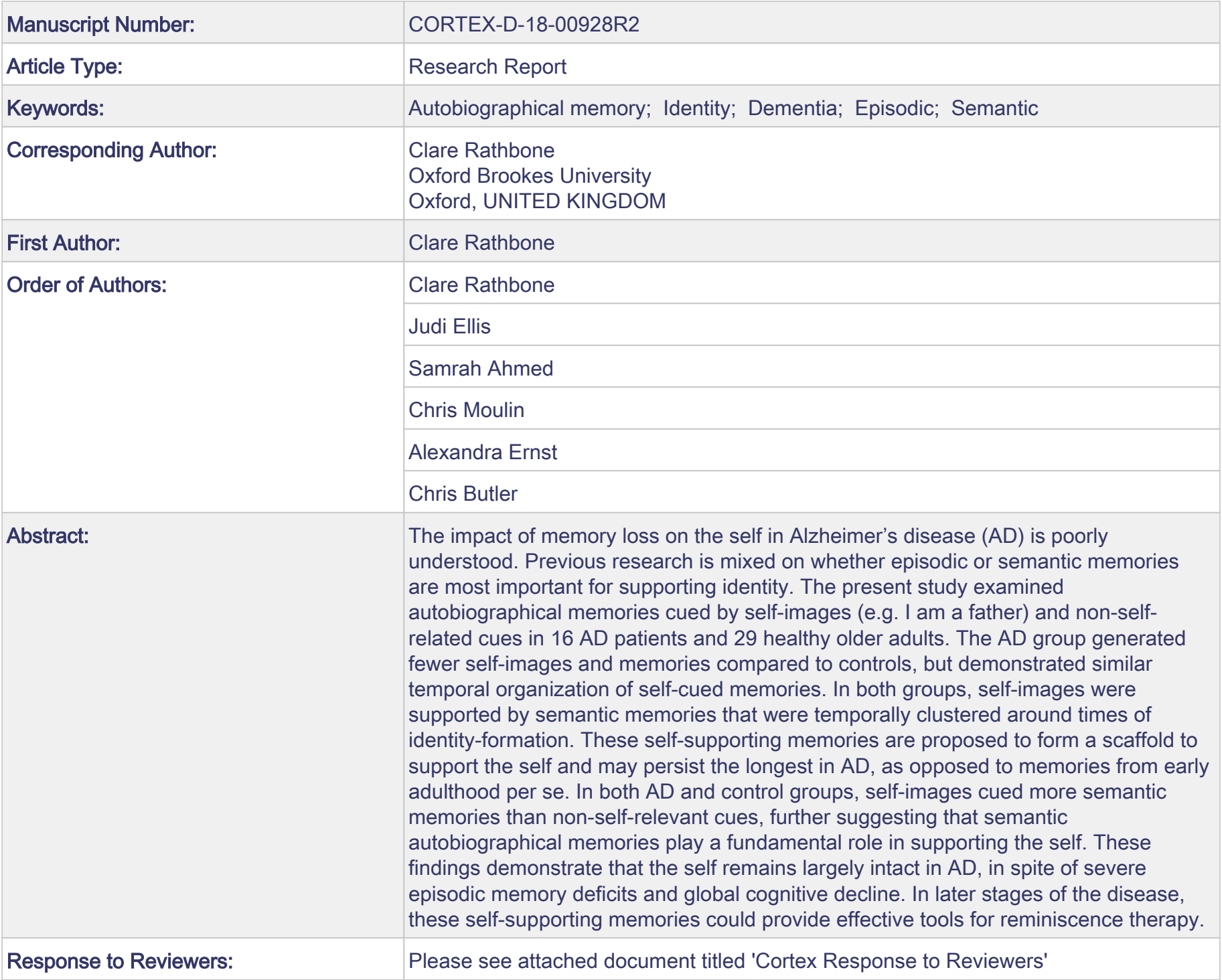


Clare J. Rathbone ${ }^{1}$, Judi A. Ellis ${ }^{2}$, Samrah Ahmed ${ }^{3}$, Chris, J.A. Moulin ${ }^{4}$, Alexandra Ernst ${ }^{4}, \&$ Chris R. Butler $^{3,5}$

1Department of Psychology, Oxford Brookes University, Oxford, UK ${ }^{2}$ University of Reading, School of Psychology and Clinical Language Sciences, Reading, UK

${ }^{3}$ University of Oxford, Nuffield Department of Clinical Neurosciences, Oxford, UK ${ }^{4}$ LPNC, CNRS UMR 5015, Université Grenoble Alpes, Grenoble, France

${ }^{5}$ Visiting Professor at the Department of Medicine, Pontificia Universidad de Chile, Santiago, Chile

Word count: 9,377

Address for Correspondence:

Clare J. Rathbone

Department of Psychology

Oxford Brookes University

Gipsy Lane

Oxford

OX3 OBP

United Kingdom

Tel. +44 (0)1865 483772 Email: crathbone@brookes.ac.uk 
Running head: Self and memory in Alzheimer's disease

Using memories to support the self in Alzheimer's disease

\begin{abstract}
The impact of memory loss on the self in Alzheimer's disease (AD) is poorly understood. Previous research is mixed on whether episodic or semantic memories are most important for supporting identity. The present study examined autobiographical memories cued by self-images (e.g. I am a father) and non-self-related cues in 16 AD patients and 29 healthy older adults. The AD group generated fewer self-images and memories compared to controls, but demonstrated similar temporal organization of self-cued memories. In both groups, self-images were supported by semantic memories that were temporally clustered around times of identity-formation. These selfsupporting memories are proposed to form a scaffold to support the self and may persist the longest in $A D$, as opposed to memories from early adulthood per se. In both $A D$ and control groups, selfimages cued more semantic memories than non-self-relevant cues, further suggesting that semantic autobiographical memories play a fundamental role in supporting the self. These findings demonstrate that the self remains largely intact in $A D$, in spite of severe episodic memory deficits and global cognitive decline. In later stages of the disease, these self-supporting memories could provide effective tools for reminiscence therapy.
\end{abstract}

Keywords: Autobiographical memory; Identity; Dementia; Episodic; Semantic 


\section{Introduction}

Developing a better understanding of the impact of memory loss on identity in Alzheimer's disease (AD) is a fundamental issue for our aging society. Worldwide, the number of people with dementia is predicted to increase from 50 million in 2018 to 152 million in 2050 (World Health Organization, 2017). However, whilst a growing body of research has attempted to examine the relationship between memory and identity in dementia there are mixed findings in the literature, particularly regarding the impact of memory loss on identity and the role that episodic and semantic autobiographical memories might play in supporting the self. This paper presents a novel investigation of the memories that support identity in dementia. It aims to examine (1) how identity is impacted by $A D,(2)$ how memories are temporally organised to support identity in $A D$, and (3) whether episodic or semantic memories play a more fundamental role in supporting identity in both $A D$ and healthy aging.

There is widespread evidence for autobiographical memory impairments in AD, particularly an episodic deficit marked by impaired episodic retrieval (i.e. recollection of vivid details for specific events) and relatively intact semantic memory (i.e. knowledge of self-relevant facts and general events experienced) in the early to middle stages of the disease (Ahmed et al., 2018; El Haj, Antoine, Nandrino \& Kapogiannis, 2015; Greene, Hodges \& Baddeley, 1995; Seidl et al., 2011). Furthermore, research suggests that $A D$ is associated with a reduced self-reference effect (i.e. enhanced recall for material encoded in reference to the self; Rogers, Kuiper \& Kirker, 1977), suggesting impaired memory processing of self-related material (Genon et al., 2014; Wong et al., 2017). Thus, AD seems to be associated with a number of marked changes in memory processing, particularly for memories associated with the self.

Given theoretical models of self and memory (e.g. the Self-Memory System, Conway \& PleydellPearce, 2000), and the philosophical view that self and memory are intimately linked (e.g. Locke, 1694/1975), one might expect that memory impairment would lead to changes in, if not loss of, the 
self. Of relevance here is the fact that the term 'self' is multifaceted and has been used to refer to a wide variety of psychological functions and processes (Caddell \& Clare, 2011b). For example, Klein (2012) notes that the self is associated with a range of neurocognitive systems, including episodic memories, semantic knowledge of personality traits, semantic facts about one's life, diachronic unity (i.e. the way experiences are unified over time), sense of agency, and the ability to self reflect, experience emotion and recognise ones physical self in a mirror or photograph. For clarity, in the present study we use the term self to refer to knowledge about the self in the form of 'self-images' (Rathbone et al., 2015), encompassing personality traits, social roles (e.g. being a father, teacher, friend), hobbies, and likes/dislikes.

The idea that memory and self are bi-directionally linked is central to Conway's Self Memory System Model (Conway, 2005; Conway \& Pleydell-Pearce, 2000), which proposes that the self has an executive function, organizing access to autobiographical memories, as well as being constrained and shaped by the memories that are retrieved. Thus, one might expect that an inability to retrieve autobiographical memories would be associated with a reduced ability to generate self-images. In support of this proposal, Addis and Tippett (2004) found that patients with AD produced fewer 'I am' statements (i.e. self-images) compared to age matched controls. Furthermore, the patients' memory impairments were correlated with changes in the strength and quality of identity - patients with AD who demonstrated the largest deficits in memories for childhood and early adulthood also showed reduced identity strength (producing fewer 'I am' statements) and changes in the quality of identity (using more definite responses on the Tennessee Self Concept Scale and generating a higher proportion of abstract 'I am' statements).

A number of other studies have suggested that $A D$ is associated with impairments in some aspect of self or identity (e.g. Fargeau et al., 2010) and particularly with problems updating knowledge about the self after disease onset (Harrison, Therrien \& Giordani, 2005; Hehman, German \& Klein, 2005; Klein et al., 2003; Klein \& Gangi, 2010; Morris \& Mograbi, 2013; Rankin et al., 2005). Mograbi, Brown 
and Morris (2009) proposed that the memory impairments associated with dementia, specifically

the better preservation of remote compared to recent events, may lead to a failure to update knowledge about the self. This 'petrified self' hypothesis is proposed by Mograbi et al. to explain the anosognosia (lack of awareness of illness/impairment) frequently evident in dementia. It should be noted that difficulty updating one's sense of self is not incompatible with maintaining a sense of identity, but that this identity is less accurate and outdated.

In fact, a growing literature suggests that self knowledge can persist, despite the memory impairments and global cognitive decline associated with dementia (e.g. Eustache et al., 2013; Strohminger \& Nichols, 2015). Caddell and Clare have conducted a range of studies exploring the impact of $A D$ on identity and have found no evidence for a linear relationship between cognitive function and identity (Caddell \& Clare, 2013b), that there is little difference in identity between patients in the early stage of AD and healthy older adults (Caddell \& Clare, 2013a), and that identity is often maintained in later stages of $A D$ (Caddell \& Clare, 2010). These results support a broader finding, not limited to dementia but demonstrated across various patient groups exhibiting memory deficits; namely, episodic retrieval is not necessary for self-knowledge (e.g. Klein, 2012; Klein, Rozendal \& Cosmides, 2002; Rathbone et al., 2009). These mixed findings generate a number of research questions. Firstly, if we take the view that there are clearly some important links between self and memory then what, if any, impact do the established memory changes in AD have on the way in which memories are used to support the self? Secondly, although some (or all) aspects of the self may persist, is the self qualitatively different in $A D$ compared to healthy aging? Thus, the first aim of the present study was to examine the impact of $A D$ on the phenomenological features of selfimages and of autobiographical memories that are particularly relevant to the self: self-supporting memories (memories cued by participant-generated self-images using the IAM Task; Rathbone et al., 2008). 
The second aim of this study was to examine the temporal organization of self-supporting memories

in AD. Previous research in healthy aging has shown that memories cued by self-images tend to be clustered around periods of identity formation (Chessel et al., 2014; Rathbone et al., 2008). Thus, memories associated with being a keen gardener will be most frequently dated from the time someone first became interested in gardening, and memories of being hard-working will tend to date back to the period when someone believes they first exhibited the trait of being a hard-worker. This robust effect has been replicated across a number of studies (Bennouna-Greene et al., 2012, Rathbone et al., 2008; 2011) and is suggested to support a coherent life narrative by scaffolding selfimages with sets of salient autobiographical memories. This temporal scaffolding has also been demonstrated in an amnesic case study. Patient PJM (Rathbone et al., 2009) experienced a traumatic brain injury in a cycling accident which resulted in an isolated episodic deficit. Although PJM's autobiographical memories were semantic in nature, the IAM Task showed that PJM's selfsupporting memories demonstrated the same temporal clustering as age-matched controls, suggesting that these semantic memories were used to support knowledge of self-images in the absence of episodic memories. The present study is the first to examine whether this temporal scaffolding is also demonstrated in $A D$, a disease characterised by marked episodic decline and global cognitive impairments. If temporal clustering is demonstrated then this would indicate that this particular form of self-related memory processing is intact in AD.

The third and final aim of this research was to examine whether the memories that are most relevant to the self (i.e. self-supporting) are more episodic or semantic in nature, compared to less self-relevant autobiographical memories. This experiment is the first directly to address this question, but previous related research has generated mixed results that support contrasting predictions. On the one hand, a growing number of papers suggest that semantic autobiographical memories are likely to play a central role in supporting identity. First, as discussed above, research with amnesic cases suggests that the self can be supported with semantic knowledge in the absence of episodic memory (e.g. Klein et al., 2002). In addition, using a similar method to the IAM Task, Grilli 
found that healthy young adults (Grilli, 2017), amnesic patients and healthy older adults (Grilli \&

Verfaellie, 2015) all tended to generate semantic facts, rather than episodic events, when asked to explain 'what makes you say "I am_"?' Grilli (2017) thus proposed that these semantic 'selfsupporting memories' are likely to play a prominent role in the networks of memories that support identity. Finally, Haslam et al. (2011) found that semantic autobiographical memory (as opposed to episodic) was associated with strength in personal identity. They proposed the Self-knowledge and identity model (SKIM), which places semantic self-knowledge as a bi-directional mediator between episodic self-knowledge and identity.

Other studies have emphasised the idea that selfhood is intimately linked with episodic memory. Indeed, autonoetic consciousness (the sense of oneself travelling back in time and re-living past events) is a defining feature of episodic memory (Tulving, 1985) and several studies suggest that self-related memory cues serve to enhance episodic richness (e.g. Ernst et al., 2016, El Haj et al., 2017). Miles et al., (2013) found that participants with dementia produced memories with higher ratings of episodic specificity when they were recalled in an early $20^{\text {th }}$ century museum setting (surrounded by cues associated with their youth), compared to a control setting of a typical everyday room. It is possible that the museum setting supported retrieval by providing a number of detailed, self-relevant cues, prompting spontaneous retrieval of memories rich in episodic detail (e.g. Berntsen, 2009). The impact of self-focus on retrieval in AD was tested more directly by El Haj and Antoine (2017), who assigned participants to either read about mushroom picking or complete an 'I am' task (i.e. generate self-images) and then measured episodic specificity ratings for a memory of an event in their life. Results showed that when first primed to think about the self, AD patients generated a memory with higher episodic specificity ratings compared to when they read the nonself-relevant text.

A similar effect was found in a case study by Ernst et al. (2016) who compared the episodic richness of memories generated to standard autobiographical memory cues in the TEMPau Task (Piolino et 
al., 2000) with memories cued by 'I am' statements in DR, a patient with chronic Unilateral Spatial

Neglect (USN). Although DR's episodic specificity scores were significantly lower than controls in the TEMPau task, her specificity ratings were equivalent to controls when she used 'I am' statements as cues. These results suggest that DR's episodic retrieval was enhanced by using highly self-related cues.

Finally, the field of self-defining memories (SDMs; Singer and Salovey, 1993) is based on the idea that certain specific episodic memories can become central to our identity. SDMs are a type of autobiographical memory defined as being linked to other memories, regularly rehearsed, high in emotionality and vividness, and connected to an enduring theme or unresolved conflict (Singer \& Salovey, 1993). They are proposed to combine motivational, cognitive and affective information and be highly goal-relevant (Conway, Singer \& Tagini, 2004). Of note, Martinelli, Anssens, Sperduti and Piolino (2013) found that the usual pattern of diminished episodic specificity in aging (e.g. Levine et al., 2002) was reduced when participants were instructed to generate SDMs. Older adults recalled fewer autobiographical episodes but a similar percentage of SDMs compared to younger adults. In contrast, a group with a probable diagnosis of Alzheimer's Disease demonstrated impaired recall when recalling both autobiographical episodes and SDMs.

Whilst there is no conflict between the ideas that (1) semantic memories support identity and (2) the self can facilitate access to episodic memories, the present study was motivated by an interest in the type of memories that are cued by the self. Whether the memories that support the self (relative to other types of autobiographical memory) in AD are more semantic or episodic in nature has important clinical implications. Memory rehabilitation approaches frequently involve efforts to improve the accessibility of specific episodic memories (e.g. using music as a memory cue; El Haj et al., 2012). However, if it emerges that semantic, rather than episodic, memories play a more fundamental role in supporting the self then this may imply that efforts should be directed towards raising the accessibility of semantic memories instead. Prebble, Addis and Tippett (2013) propose 
that episodic and semantic memories may support different aspects of identity, with episodic

autobiographical memories supporting phenomenological continuity (a subjective sense of selfawareness associated with a feeling of existing coherently through time) and semantic autobiographical memories supporting semantic continuity (self knowledge associated with the organization of a narrative life story). To the authors' knowledge, the present study is the first directly to compare the episodic specificity of memories cued by highly self-relevant versus less selfrelevant cues in dementia and healthy aging.

\subsection{Aims}

Our first aim was to examine the phenomenological features of self-images ('I am' statements) and self-supporting memories in Alzheimer's disease. In line with previous research (e.g. Addis and Tippett; 2004), we predicted that the AD group would generate fewer self-images and a higher proportion of abstract (trait-linked) self-images compared to a healthy older adult control group. ${ }^{i}$ We also predicted that the AD group would generate fewer self-supporting memories and that these memories would be less episodic, compared to controls (e.g. El Haj, Antoine, Nandrino \& Kapogiannis, 2015; Greene, Hodges \& Baddeley, 1995; Seidl et al., 2011). We included a number of other measures of self-images and self-supporting memories (e.g. emotional valence, vividness, personal significance, rehearsal) to examine the potential impact of $A D$ on measures associated with the self.

The second aim of this study was a novel examination of the temporal organization of selfsupporting memories in Alzheimer's disease. We predicted that self-supporting memories would cluster around periods of identity formation, in a similar distribution to healthy controls. This scaffolding effect, previously demonstrated in healthy aging and a case of episodic amnesia (Rathbone et al., 2008; 2009), is proposed to help maintain a coherent life narrative. In addition, analysis of the phenomenological features of self-supporting memories according to their temporal organization aimed to elucidate the mechanisms by which certain AMs might become self- 
supporting. It was predicted that memories closest to periods of identity formation would be more emotionally positive, vivid, rehearsed and personally significant.

The final aim of this study was to develop a novel task to compare the episodic specificity of selfsupporting memories with memories that were less self-related (i.e. generic, category-cued memories). The prediction was that self-images (compared to categories) would cue more episodic autobiographical memories, although the literature is mixed on whether memories that support identity are more likely to be episodic (e.g. El Haj \& Antoine, 2017; Ernst et al., 2016; Singer \& Salovey, 1993) or semantic (e.g. Grilli, 2017; Haslam et al., 2011). Our prediction was based on the idea that self-supporting memories, as elucidated above, are often retrieved with high levels of vividness and specificity, overcoming general declines in episodic memory (e.g. healthy aging; Martinelli et al., 2013).

\section{Method}

We report how we determined our sample size, all data exclusions, all inclusion/exclusion criteria, whether inclusion/exclusion criteria were established prior to data analysis, all manipulations, and all measures in the study."

\subsection{Participants}

The patient group comprised 16 patients $^{\mathrm{iii}}$ ( 5 female, 11 male; mean age $=68.63 ; S D=7.12$, range $=$ 56-84) diagnosed with AD, who were recruited through the Oxford Cognitive Disorders Clinic, Oxford, UK. Diagnosis was established by a senior behavioural neurologist (CRB). All patients fulfilled consensus criteria for AD (McKhann et al., 2011), based upon brain imaging, clinical assessment and detailed neuropsychological assessment. Patient MOCA scores ranged from 12-25 (Mean $=17.63$, SD $=3.98)$.

$A D$ patients were compared with 29 healthy controls ( 17 female, 12 male; mean age $=70.07 ; \mathrm{SD}=$ 3.03 , range $=65-75$; comprising a subset from data reported in Rathbone et al., 2015), recruited 
from a database of local adults interested in participating in research projects. ${ }^{i v}$ Healthy control participants were defined as having no objective cognitive impairment on neuropsychological screening tests (all scored $\geq 25$ on the MOCA; see Ahmed et al., 2011; Carson et al., 2018; Chiti \& Pantoni, 2014). Controls had no prior history of significant head injury, substance abuse or cerebrovascular disease, and were not prescribed any medication known to affect cognition. All inclusion/exclusion criteria were established prior to data analysis. AD and control patients were matched for age and years of education (see Table 1).

Table 1: Participant characteristics

\begin{tabular}{|c|c|c|c|c|c|c|c|}
\hline \multirow[b]{2}{*}{ Measure } & \multicolumn{2}{|c|}{ AD group } & \multicolumn{2}{|c|}{ Control group } & \multirow[b]{2}{*}{$T$} & \multirow[b]{2}{*}{$p$} & \multirow[b]{2}{*}{ Cohen's $d$} \\
\hline & $M$ & $S D$ & $M$ & $S D$ & & & \\
\hline Age & 68.63 & 7.12 & 70.07 & 3.03 & -.77 & .45 & 0.26 \\
\hline Years of Education & 14.25 & 2.35 & 14.62 & 3.60 & -.42 & .68 & 0.12 \\
\hline MOCA & 17.63 & 3.98 & 27.38 & 1.61 & $-9.39 *$ & $<.001$ & 3.21 \\
\hline \multicolumn{8}{|l|}{ Cognitive Battery } \\
\hline Vocabulary & 39.31 & 9.60 & 47.79 & 9.27 & -2.90 & .006 & 0.90 \\
\hline Letter fluency & 12.94 & 5.71 & 16.69 & 4.71 & -2.37 & .022 & 0.72 \\
\hline Category fluency & 12.38 & 4.97 & 21.38 & 4.64 & $-6.08 *$ & $<.001$ & 1.87 \\
\hline LM immediate & 14.81 & 8.38 & 35.66 & 8.34 & $-8.01^{*}$ & $<.001$ & 2.49 \\
\hline
\end{tabular}


LM delayed

LM recognition

Rey copy

Rey recall

Rey delayed recall

Naming

AMI semantic

AMI episodic

EMQ

Well-being scales

PANAS positive

PANAS negative

SWLS

LOT-R

HADS

\subsection{3}

14.00

25.50

3.81

3.03

17.13

52.03

17.50

55.25

.660
26.45

49.31

30.14

3.57

6.01

8.68

5.13

5.56

35.93

5.89

6.71

8.05

$5.73 \quad 16.96$

24.03
$-1.69$

.099

0.53

7.19
4.37

4.80

16.21

9.31

4.17

3.23

$-1.26$

$-1.49$
3.51

3.01

21

Note. $\mathrm{LM}=$ Logical memory; $\mathrm{MOCA}=$ Montreal Cognitive Assessment; $\mathrm{AMI}=$ Autobiographical memory interview; $\mathrm{EMQ}=$ Everyday memory questionnaire; $\mathrm{PWB}=$ Psychological well-being; PANAS = Positive and Negative Affect Schedule; SWLS = Satisfaction with Life Scale; LOT $-\mathrm{R}=$ Life Orientation Test-Revised; HADS = Hospital Anxiety and Depression Scale (total score used). Degrees of freedom = 43 for all measures apart from PANAS positive $(d f=42)$, PANAS negative $(d f=41)$, and LOT-R $(d f=$ 42). ${ }^{*} p<.002$ (Bonferroni correction for multiple comparisons). 
Cognitive function was measured using a battery of tasks. Vocabulary was assessed using a sub-test

of the WAIS-R (Wechsler, 1981), and fluency by the number of animals (category) and words beginning with 'F' (letter) generated in one minute (Tombaugh, Kozak, \& Rees, 1999). The Autobiographical Memory Interview (AMI; Kopelman et al., 1989) assessed episodic and semantic autobiographical memory, the Logical Memory Test (LMT; subtest of Wechsler Memory Scale $3^{\text {rd }}$ edition, Wechsler, 1997) assessed recall and recognition for narrative memory, the Rey-Osterrieth Complex Figure Test (Osterrieth, 1944; Rey, 1941) assessed visuospatial memory, the Graded Naming Test (GNT; McKenna \& Warrington, 1983) measured semantic memory for object names, and the Everyday Memory Questionnaire (EMQ; Sunderland, Harris \& Gleave, 1984) was a selfreport measure of day-to-day memory problems. ${ }^{v}$

Mood and well-being were assessed using the Positive and Negative Affect Schedule (PANAS; Watson et al., 1988), Satisfaction with Life Scale (SWLS; Diener et al., 1985), Life Orientation TestRevised Optimism Scale (LOT-R; Scheier, Carver, \& Bridges, 1994), and Hospital Depression and Anxiety Scale (HADS; Zigmond \& Snaith, 1983). For details of participant characteristics see Table 1. In summary, there were no significant differences between control and AD groups' well-being scores or self-reported memory problems (i.e. EMQ score). We found expected differences in the cognitive battery, with the control group performing better than AD patients on all measures, in line with the characteristic cognitive profile in $A D$. Consistent with $A D$ criteria, patients were impaired on measures of fluency, episodic and semantic memory, and narrative and visuospatial memory, with impaired overall global function as per the MOCA.

\subsection{Materials and Procedure}

All participants completed the IAM task (Rathbone et al., 2008), Categories task, measures of wellbeing and cognitive battery (described above) in two lab-based sessions that lasted between 1.5 and 2 hours each. Session 1 comprised the IAM and Categories Task and session 2 the cognitive battery 
and well-being scales. No part of the study procedures or analyses were pre-registered prior to the research being conducted.

\subsubsection{IAM Task}

Participants verbally generated up to ten 'I am' statements (i.e. self-images). There was no time limit for this part of the task, but participants were instructed that it would take approximately 5 minutes. Once at least three 'I am' statements had been generated, participants were prompted only once if they were unable to generate more (prompt: "Are you sure you can't think of any more? They can be about anything that reflects who you are - hobbies, your personality, about your relationships with other people."). After 'I am' statement generation, participants selected their two most important statements as cues for up to five specific autobiographical memories per statement (generating up to 10 memories in total). All memories were dated for age at event, and rated on an 11-point scale for emotional valence $(-5=$ very negative,$+5=$ very positive $)$, personal significance $(0$ $=$ not at all personally significant, $10=$ very personally significant $)$, vividness $(0=$ not at all vivid, $10=$ very vivid), and rehearsal ( $0=$ never think about it, $10=$ think about it all the time). Episodic specificity ratings were collected in two ways. Participants were provided with standardised Remember/Know/Guess definitions (Gardiner, 1988) and asked to rate whether each memory was something they remembered (R), knew (K) or guessed (G). All responses rated as $R$ were probed for episodic details, and were rated as Justified Remember (JR) if such details were provided (e.g. Piolino et al., 2003). Episodic specificity was also measured by the researcher using a 0 to 4 scale (Baddeley \& Wilson, 1986), in which $4=$ a specific event with details and situated in time and space, $3=a$ specific event without any detail but situated in time and space, 2 = a repeated or extended event situated in time and space, 1 = a repeated or extended event not situated in time and space, and $0=$ no memory given / only general information about the topic.

All self-images were rated by the participant for age of self-emergence (i.e. age when each selfimage first became part of a participant's identity), emotional valence $(-5=$ very negative,$+5=$ very 
positive), and importance $(0=$ not at all important, $10=$ very important $)$. All self-images were coded by CJR according to Rhee et al.'s (1995) self-description coding scheme. Three identity scores were calculated (e.g. Addis \& Tippett, 2004; Rhee et al., 1995): identity strength (number of self-images generated, up to a maximum of 10), identity complexity (number of different identity categories sampled e.g. traits, social identities, physical descriptions, up to a maximum of eight), and identity quality (proportion of self-images coded as abstract e.g., traits or emotional states).

\subsubsection{Categories Task}

Participants generated up to five memories cued by the word 'journey' and five cued by 'an event linked with another person' (based on cues in the TEMPau task; Piolino, Desgranges \& Eustache, 2009). As in the IAM Task, participants were explicitly asked to generate five memories for each of the two cues. These ten memories were rated by the participant and CJR using the same scales as for the IAM Task and were generated using identical instructions: It is very important that the memory is of a specific event that you can bring to mind, lasting minutes or hours, but no longer than a day. As I just mentioned, the memory should be at least 1 year old. The order of the Categories Task and IAM Task was counterbalanced.

\section{Results}

\subsection{Self-image analysis}

Our first aim was to examine the features of self-images and self-supporting memories in AD.

Participants produced between 3 and 10 self-images out of a possible 10 (AD group range $=3$ to 10 ; control group range $=4$ to 10). Table 2 shows participants' mean ratings for self-image emotional valence, importance, age of self-emergence and mean measures of identity strength (the number of selves generated), complexity and quality.

Table 2: Mean ratings for self-image ratings and identity scores 


\begin{tabular}{|c|c|c|c|c|c|c|c|}
\hline Measure & $M$ & $S D$ & $M$ & $S D$ & $t$ & $p$ & Cohen's $d$ \\
\hline $\begin{array}{l}\text { Self emotional } \\
\text { valence }\end{array}$ & 3.65 & 1.74 & 2.67 & 1.51 & 1.98 & .054 & 0.60 \\
\hline Self importance & 8.05 & 1.72 & 7.41 & 1.37 & 1.36 & .181 & 0.41 \\
\hline $\begin{array}{l}\text { Age of self- } \\
\text { emergence }\end{array}$ & 28.90 & 12.86 & 26.50 & 10.61 & .673 & .504 & 0.20 \\
\hline Identity strength & 7.31 & 2.24 & 9.69 & 1.17 & $-3.95^{*}$ & .001 & 1.33 \\
\hline Identity complexity & 3.00 & .97 & 3.28 & .80 & -1.03 & .309 & 0.31 \\
\hline Identity quality & .11 & .16 & .33 & .30 & $-3.34 *$ & .002 & 0.92 \\
\hline
\end{tabular}

Note. Self emotional valence, self importance and age of self-emergence were calculated based on participants' mean self-image ratings for all self-images generated; these means were used to calculate group means. Measures of Identity strength, complexity and quality were scored for each participant and used to calculate group mean scores. Degrees of freedom $=43$ for all measures. ${ }^{*} p$ $<.008$.

As the analysis in Table 2 involved six comparisons, the adjusted cut-off for significance was $p<.008$.

The only scores to differ between $A D$ and control groups were identity strength (i.e. number of selfimages generated) and identity quality (i.e. proportion of abstract statements generated). These results suggest that the $A D$ and control groups rated their self-images similarly for emotional valence and importance, dated them as emerging at a similar age, and sampled an equivalent number of identity categories (i.e. identity complexity). AD patients generated significantly fewer self-images compared to controls and a significantly smaller proportion of the AD group's self-images were rated as abstract (e.g. trait-linked) identities. ${ }^{\text {vi }}$ 


\subsection{Phenomenological features of self-supporting memories}

Participants produced between 3 and 10 memories out of a possible 10 (AD group range $=3$ to 10 ;

control group range $=7$ to 10 ). To compare the mean ratings of self-supporting memories generated by $A D$ and control groups, a series of independent samples $t$-tests were conducted on the eight memory measures shown in Table 3.

Table 3: Mean number of memories generated and ratings for self-supporting memories

\begin{tabular}{|c|c|c|c|c|c|c|c|}
\hline \multirow[b]{2}{*}{ Measure } & \multicolumn{2}{|c|}{$A D$ group } & \multicolumn{2}{|c|}{ Control group } & \multirow[b]{2}{*}{$t$} & \multirow[b]{2}{*}{$p$} & \multirow[b]{2}{*}{ Cohen's $d$} \\
\hline & $M$ & $S D$ & $M$ & $S D$ & & & \\
\hline Memories generated & 7.00 & 2.66 & 9.86 & .58 & $-4.25^{*}$ & .001 & 1.49 \\
\hline Emotional valence & 3.34 & 1.51 & 1.97 & 1.45 & $2.99 *$ & .005 & 0.93 \\
\hline Personal significance & 6.94 & 1.62 & 6.01 & 2.02 & 1.58 & .122 & 0.51 \\
\hline Vividness & 6.67 & 2.26 & 6.77 & 1.92 & -.15 & .878 & 0.05 \\
\hline Rehearsal & 3.38 & 1.88 & 2.58 & 1.31 & 1.52 & .143 & 0.49 \\
\hline Age at event & 40.36 & 14.60 & 42.76 & 9.97 & -.65 & .518 & 0.19 \\
\hline Episodic specificity & 2.72 & .75 & 3.52 & .44 & $-4.52^{*}$ & $<.001$ & 1.30 \\
\hline Proportion JR & .57 & .28 & .83 & .19 & $-3.67^{*}$ & .001 & 1.09 \\
\hline
\end{tabular}

Note. Emotional valence rated -5 (very negative) to +5 very positive); personal significance, vividness and rehearsal all rated 0 (minimum) to 10 (maximum); age at event given in years; episodic specificity = score between 0 (minimum) and 4 (maximum, e.g. Baddeley and Wilson, 1986); proportion JR = proportion of memories generated rated as justified remember (i.e. containing episodic details, e.g. Piolino et al., 2003). Degrees of freedom $=43$ for all measures. ${ }^{*} p<.006$. 
These results indicate that there was no significant difference between $A D$ and control groups on ratings of personal significance, vividness, rehearsal or age at event. Correcting for multiple comparisons (with adjusted significance cut-off $p=.006$ ), the AD group generated fewer memories than controls, rated their memories as more positive, and their memories were less episodic in terms of both subjective (proportion rated justified remember) and more objective (episodic specificity scores) measures.

\subsection{Organization of self-supporting memories}

The second aim of this study was to examine the organisation of self-supporting memories in AD. Previous work has shown that memories that support the self are distributed in a temporal cluster (e.g. Rathbone et al., 2008; 2009; 2011), forming a scaffold for self-knowledge. This study is the first to examine whether this organisation exists in AD. In order to explore the distribution of selfsupporting memories, each dated memory was converted to an age relative to the participantselected age of self-emergence for each self-image (e.g. Rathbone et al., 2008). Thus, all memories were given either a positive score (occurring after self-emergence for the relevant self-image) or a negative score (occurring before self-emergence for that self-image), or 0 if they occurred in the same year as the age of self-emergence. For example, for the self-image 'I am a father' which emerged at 35, a memory of looking after a daughter with chicken pox aged 40 would be reformulated as 5 . To analyse these data, they were split into 10 bins: $(<-24,-24$ to $-15,-14$ to $-5,-4$ to 5,6 to 15,16 to 25,26 to 35,36 to 45,46 to $55,>55$ ). Figure 1 shows the mean frequency of memories generated across bins in each group. 


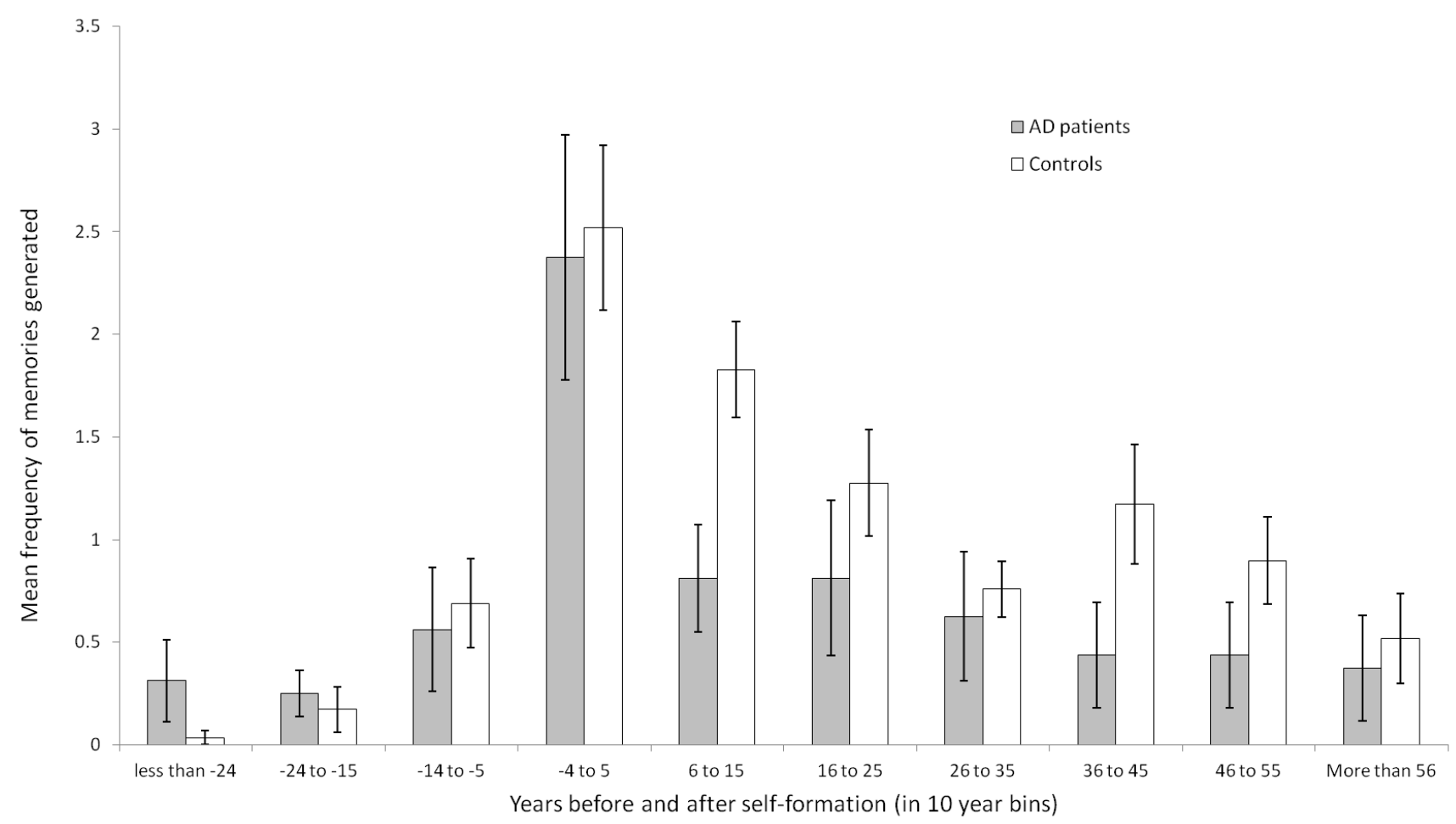

Figure 1: Mean frequency of memories in 10 year bins around self-formation in AD patients and controls (error bars show standard error)

Figure 1 shows a clear centering of memories around the bin of self-emergence ( 4 years before to 5 years after self-emergence) in both the AD group and controls. A mixed ANOVA comparing memory distributions (i.e. frequency of memories in each of the 10 bins) with group as a between subjects factor revealed a main effect of bin $\left(F(9,387)=10.46, p<.001\right.$, partial $\left.\eta^{2}=.20\right)$, a main effect of group $\left(F(1,43)=31.46, p<.001\right.$, partial $\left.\eta^{2}=.42\right)$, and no group $x$ bin interaction $(F<1)$. Bonferronicorrected pairwise comparisons showed that the bin of central interest, -4 to +5 years around selfemergence, was associated with a significantly higher frequency of memories compared to six of the nine other bins. ${ }^{\text {vii }}$ As Figure 1 demonstrates, for both groups the bin associated with self-emergence is associated with the highest frequency of memories. When examined proportionally, this central bin comprises $26 \%$ of control group memories and $32 \%$ of AD group memories respectively. ${ }^{\text {vii }}$ 


\subsection{Relationship between self and memory}

Having established that self-supporting memories are distributed in similar ways in both control and AD groups, we carried out further analyses to explore potential mechanisms underlying this organisation. The AD group produced significantly fewer self-supporting memories than controls, and these were significantly less episodic, as measured by both JR rating and episodic specificity score. However, as shown in Figure 1, the AD group's memories are organised in a similar way to controls', with the highest proportion of memories dated in the period of identity formation (i.e. bin -4 to 5 years around self-emergence). This suggests that the memories that remain accessible in AD are those that are important to the self. To test the idea that memories dated closest to periods of self-emergence are phenomenologically distinct, we examined whether memories dated closest to self-emergence were rated as more personally significant, vivid, rehearsed or positive.

As there were no significant differences between $A D$ and control group memory ratings for personal significance, vividness or rehearsal, these measures were examined for both groups combined (i.e. on all 398 memories generated in total) in relation to unsigned distance in years from self emergence. To correct for multiple correlations, a significance cut-off of 0.017 was used. There was a significant negative correlation between unsigned distance from self-emergence and personal significance $(R[398]=-.16, p=.002)$, suggesting that memories dated closest to self-emergence are rated as more personally significant. There was no significant relationship between unsigned distance and vividness $(R[398]=-.08, p=.138)$ or rehearsal $(R[398]=.07, p=.17)$. As the AD group's ratings for memory emotional valence were significantly higher than controls, the relationship between unsigned distance from self emergence and emotional valence was analysed in each group separately. In the control group there was a significant negative correlation between unsigned distance from self-emergence and memory emotional valence $(R[286]=-.18, p=.003)$, but this relationship was not significant in the $\mathrm{AD}$ group $(R[112]=.02, p=.809)$. A Fisher's $r$-to-z transformation showed no significant differences between these correlations for $A D$ and control 
groups ( $z=-1.79, p=.073$, two-tailed), suggesting the AD group showed a similar pattern to controls but was potentially under-powered for this analysis.

\subsection{Self-supporting memories compared to category-cued memories}

The final aim of this study was to compare the episodic specificity of self-supporting memories compared to those that were less self-related (i.e. category-cued memories). The mean number of self-cued memories generated in each group is shown in the top line of Table 3. For category-cues, again the $A D$ group generated fewer memories $(M=8.25, S D=2.41)$ compared to controls, who all generated 10 memories. The AD group mean was significantly lower than $10(t[15]=-2.91, p=.011)$. There was no significant difference between the number of memories generated to category cues versus self-cues within the $\mathrm{AD}(p=.13)$ or control group $(p=.21)$.

The following analysis was based on mean group episodic specificity scores and proportion JR scores for self-cued memories compared to category-cued memories. Figure 2 shows mean episodic specificity scores (upper panel) and proportion JR scores (lower panel) for both AD and control groups.

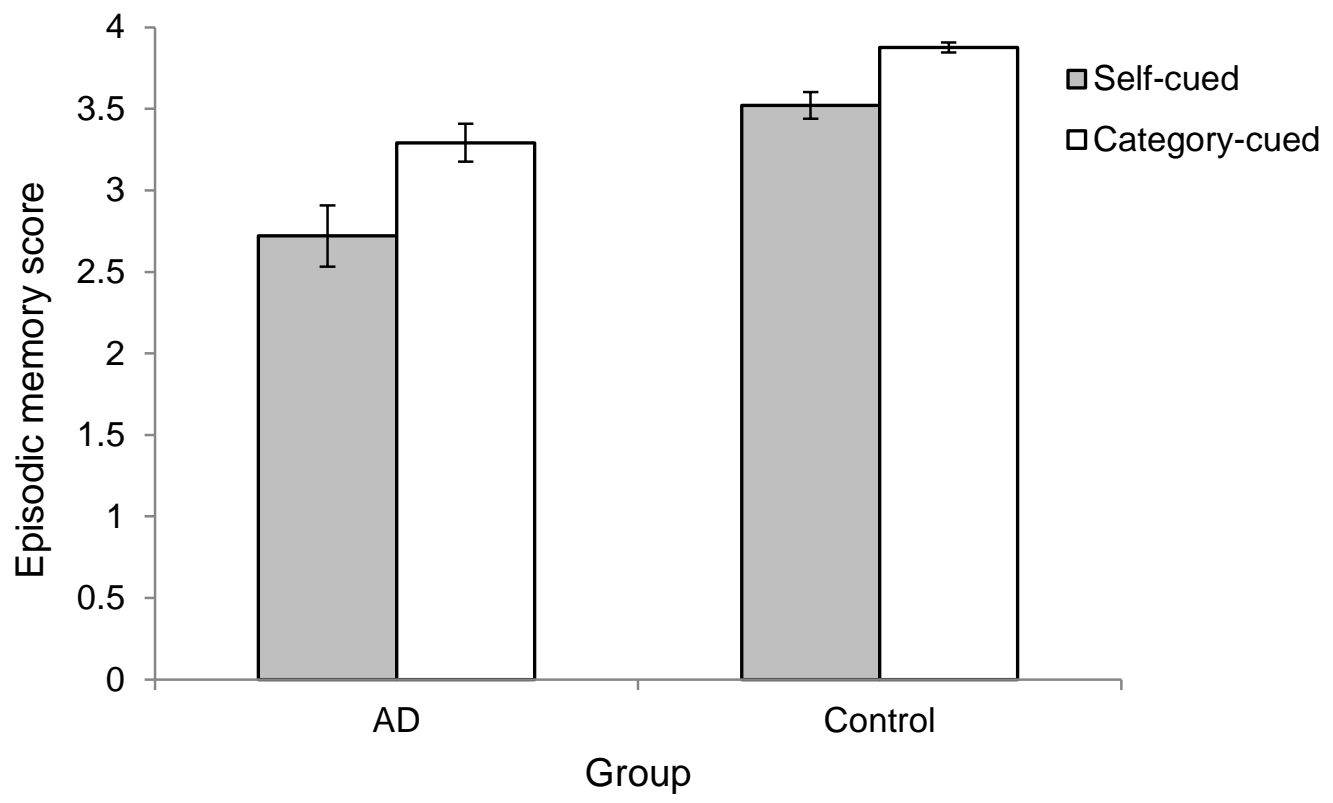




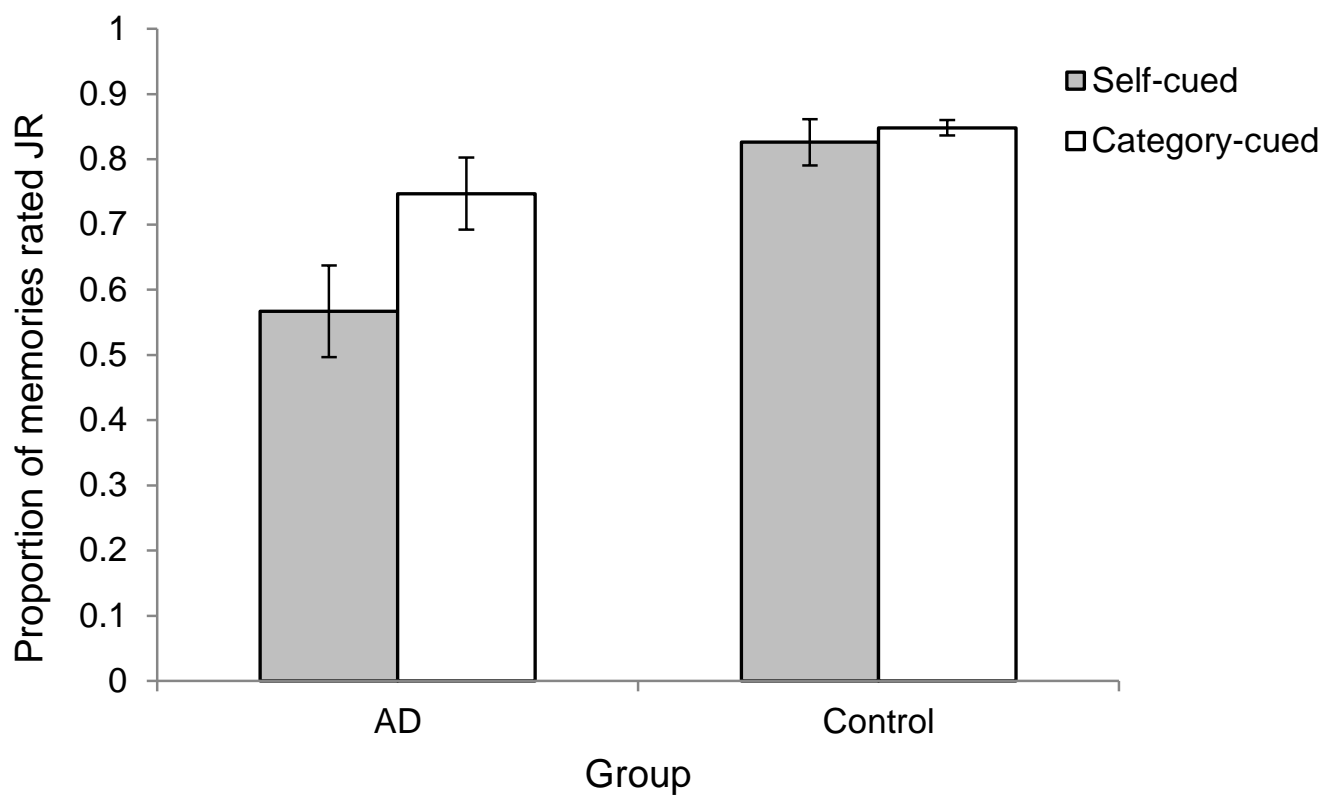

Figure 2: Mean episodic specificity scores (upper panel) and proportion JR scores (lower panel) for AD patients and controls according to type of memory cue (error bars show standard error)

These scores were analysed using mixed ANOVAs comparing group (AD and control) and task (selfcued and category-cued). For episodic specificity scores there was a main effect of group $(F[1,43]=$ $39.83, p<.001$, partial $\left.\eta^{2}=.48\right)$, a main effect of task $\left(F[1,43]=26.16, p<.001\right.$, partial $\left.\eta^{2}=.38\right)$ and no group $x$ task interaction $\left(F[1,43]=1.43, p=.24\right.$, partial $\left.\eta^{2}=.03\right)$. This shows that the control group's memories were generally rated as more episodic compared to the AD group and that, for both groups, the category-cue task produced memories that were rated higher for episodic specificity compared to the self-image task.

To examine whether lower specificity scores in the AD group were driven by less detailed episodic memories (scored 3) or semantic memories (scored 0-2) the proportion of memories scored 0-2 in each group was analysed for self-cued and category-cued memories. For self-cued memories, the $A D$ group generated a significantly higher proportion of memories scored $0-2(M=.42, S D=.24)$ compared to controls $(M=.16, S D=.17) t(43)=4.25, p<.001, d=1.25$. Similarly, for category-cued 
memories the $A D$ group generated a significantly higher proportion of memories scored $0-2(M=$ $.26, S D=.19)$ compared to controls $(M=.04, S D=.06) t(43)=5.82, p<.001, d=1.56$. Thus, the AD group generated more memories that were semantic, not simply memories that were less episodically detailed, compared to controls. Paired sample t-tests show that a significantly higher proportion of self-cued memories were scored 0-2 compared to category-cued memories in both the $\operatorname{AD}$ group $(t(15)=2.61, p=.02, d=0.76)$ and control group $(t(28)=3.64, p=.001, d=0.93)$. For proportion JR scores, there was a main effect of group $\left(F[1,43]=14.88, p<.001\right.$, partial $\left.\eta^{2}=.26\right)$, a main effect of task $\left(F[1,43]=8.13, p=.007\right.$, partial $\left.\eta^{2}=.16\right)$ and a significant group $\mathrm{x}$ task interaction $\left(F[1,43]=4.95, p=.031\right.$, partial $\left.\eta^{2}=.10\right)$. This shows that, again, the control group generated more specific memories (i.e. a higher proportion rated as 'justified remembered') compared to the AD group and that the category-cue task generated a higher proportion of JR-rated memories than the self-image task. The interaction suggests that the effect of task differed for AD patients compared to controls. Post hoc $t$-tests show there was no significant difference between groups' proportion JR scores when the task involved generating memories to category cues $(t[16.38]=-1.79, p=.09)$ but that in the self-image cued task AD patients generated a significantly lower proportion of JR-rated memories compared to control participants $(t[43]=-3.67, p=.001, d=$ 1.08). Thus, results using both measures of episodic specificity show that all participants tended to generate less episodically rich memories to self-image cues compared to category-cues. This effect was particularly pronounced for AD patients, as their proportion JR scores were only significantly lower than those of controls when generating memories to self-image cues.

In order to eliminate alternative interpretations of these findings, we carried out additional analyses on the mean age at event for category cued and self-cued memories. In both groups the mean age at event was younger (i.e. more distant) for category-cued, compared to self-cued memories (Controls self-cued mean memory age $=42.76(S D=9.97)$, Controls category-cued mean memory age $=38.04(S D=10.63) ; A D$ self-cued mean memory age $=40.36(S D=14.60), A D$ category-cued 
mean memory age $=32.56(S D=11.08))$. Paired sample t-tests showed no significant difference in age at event for memories cued by self-images compared to category cues in the control group $(t(28)=-1.78, p=.08)$, but indicated that in the AD group memories cued by self-images were significantly more recent than those generated to category cues $(t(15)=-2.91, p=.01, d=0.60)$. As one would expect more recent memories to have higher, as opposed to lower, ratings of episodic specificity, variability in recency scores does not explain the pattern of results found for episodic specificity.

\section{Discussion}

Our first aim was to examine the phenomenological features of self-images and self-supporting memories in $A D$. As predicted, we found that the AD group generated fewer self-images and fewer, less episodic, memories compared to controls. Unexpectedly, and in contrast to Addis and Tippett (2004), the AD group generated a significantly lower proportion of abstract (i.e. trait-linked) selfimages than controls. In other respects, there was little difference between the ratings for selfimages and self-supporting memories between groups, although the AD group rated their selfsupporting memories as significantly more emotionally positive than controls.

The second aim of this study was to examine the organisation of self-supporting memories in AD. As predicted, the AD group's self-supporting memories were organised in a similar way to the control group's memories, with memories most frequently dated around periods of self-emergence. Further correlational analyses indicated that memories dated closest to self-emergence were more personally significant and, in controls, more positive. These results suggest that autobiographical memories are used to scaffold the self, potentially aiding access to salient and positive selfknowledge across the lifespan and - in the AD group - in spite of pronounced cognitive deficits. Against predictions, there was no significant relationship between distance from self-emergence and ratings of memory vividness or rehearsal. 
The final aim of this study was to compare the episodic specificity of self-supporting memories

compared to those that were less self-related (i.e. category-cued memories). Counter to predictions, we found that memories cued by self-images tended to be less episodic compared to memories cued by categories, in both $A D$ and control groups. There are a number of possible explanations for this finding which are discussed later in this section.

First, these findings support previous research suggesting that identity generally remains intact in AD, at least in the early stages (e.g. Caddell \& Clare, 2010; 2013a). Although there were differences in the number and abstract/specific nature of self-images between groups, on all other measures the self in $A D$ was similar to in healthy aging. This raises the interesting question of which specific aspects of identity are most important for maintaining a self-concept. Notably, in the present study the AD group demonstrated similar levels of well-being to controls (as measured by the Satisfaction with Life Scale, Positive and Negative Affect Schedule, Life Orientation Test-Revised and Hospital Anxiety and Depression Scale). One interpretation of this finding is that the AD group's relatively positive outlook indicates an intact and well-functioning sense of self. Thus, generating fewer selfimages (or self-images that are qualitatively different) is not detrimental to one's identity overall. Theoretical models such as that put forward by Klein (2002) suggest that the ability to recall episodic memories is not a fundamental requirement for maintaining a sense of self. The results of the present study support this view and suggest that an ability to generate a few core semantic facts about the self (i.e. self-images) may be a key component of maintaining self-continuity.

Interestingly, self-supporting memories were rated significantly more positively in the AD group which may reflect a motivation to self-enhance - a protective mechanism identified in other neuropsychological cases of memory impairment (Fotopoulou et al., 2007). As fewer memories are accessible overall to the AD group, it may be that more peripheral memories are lost whilst those that are most important and self-enhancing remain. This proposal is supported by the correlational results showing that memories closest to periods of identity formation (i.e. self-emergence) were 
more personally significant and, in controls, more positive. These correlational results should be interpreted with a degree of caution, as it is likely that the rating scales used are not independent of each other (i.e. memories that are more personally significant are likely to be more positive and more vivid). However it is important to note that our main focus is on how these Likert variables relate to distance from self-emergence, rather than to each other. This distance variable (based on a calculation using two separate dates) is likely to be independent enough from the Likert scale variables (e.g. personal significance) to be worthy of examination.

The temporal clustering of memories around identity formation is proposed to demonstrate the organisation of memories to support self-knowledge. In line with Conway's (2005) bi-directional model of self and memory, this scaffolding process may work both ways. Thus, whilst memories may be organised (i.e. be particularly accessible) around self-images, these same self-images may in turn activate and organise sets of relevant memories. (The findings in the current study do not allow inferences about the direction of the relationship between self-knowledge and memories.) The idea that self-images form a scaffold for memories is supported by the semantic scaffolding hypothesis, which posits that the ability to construct memories and imagined future events requires a scaffold or framework of semantic knowledge - a proposal supported by the finding that patients with semantic dementia show deficits when constructing novel future events (Irish et al., 2012). Here we suggest that semantic knowledge about the self forms a temporal and thematic scaffold for semantic and episodic autobiographical memories, in line with others who have proposed that people use semanticised life story chapters (e.g., working at a particular university) to organise autobiographical retrieval and shape a narrative life story (Thomsen, 2009; Thomsen, Pillemer \& Ivcevic, 2011). This finding also reflects the increase in memories sampled from the start and end of life-story chapters (an 'end-point effect' identified by Thomsen \& Berntsen, 2005), which may reflect narrative processes that support semantic continuity and a coherent identity (Prebble et al., 2013). 
Prebble and colleagues (Addis \& Tippett, 2008; Prebble, Addis and Tippett, 2013; Tippett, Prebble

and Addis, 2018) propose that narrative continuity of identity may be supported by semantic autobiographical memory, such that even those with severe episodic deficits are able to experience a coherent sense of self through time if their semantic facts are organised into a coherent life story. The results of the present study are relevant to this proposal, as they demonstrate clear self-related memory organisation in dementia, in memories that are rated as more semantic in nature. This study is the first to show that this form of self-related memory organisation remains intact in $A D$, in contrast to other self-related memory processes, such as the self-reference effect, which are impaired in this group (Genon et al., 2014; Wong et al., 2017).

Against predictions, in both $A D$ and healthy aging, memories cued by self-images were more semantic in nature than those cued by less self-relevant cues. In the AD group this effect was particularly pronounced. This finding supports previous work that has emphasised the important role of semantic memory in supporting the self (e.g. Grilli, 2017; Haslam et al., 2011; Klein et al., 2002) and reflects the idea that self-knowledge comes in many forms (e.g. Klein, 2012) and not all require episodic memory.

In fact, we also replicated this effect with a younger adult cohort who completed the categories and IAM tasks during a separate study (Rathbone et al., 2015). These results are presented in the supplementary material. This indicates that using semantic memories to support the self is not simply an aging effect, or associated with a general tendency to generate semantic rather than episodic memories. These findings support the idea that the self is a semantic structure, indexing access to hierarchies of semantic memories that scaffold the self (Conway, 2005). Indeed, recent work in the emerging field of personal semantics, defined as semantic knowledge of one's past (Renoult et al., 2012; 2016), is beginning to uncover the ways in which personally relevant semantic information might differ from both episodic autobiographical memory and more general semantic 
memory. We propose that future work is needed to provide a better understanding of the role of personal semantics in supporting self and well-being across the lifespan and in clinical groups.

The present findings also contrast with previous work in $A D$ that has emphasised the role of episodic memory in relation to the self. For example, El Haj and Antoine (2017) found that memories with higher ratings of episodic specificity were generated following a self-image generation task compared to a text reading task. However, there are a number of key differences between the present study and that conducted by El Haj and Antoine. First, whilst we used self-images as memory cues, El Haj and Antoine used self-image generation as a priming task to activate the self (compared to a text reading control task), and then instructed participants after both tasks to 'recount in detail an event in your life.' Because the control condition in El Haj and Antoine's study did not involve memory or the self, it is difficult to know whether it is the self-related nature of generating 'I am' statements that enhanced episodic specificity, or some other feature of producing verbal statements as opposed to reading a text. In addition, we sampled up to 10 memories per condition per participant, whereas El Haj and Antoine sampled one. Nevertheless, these contrasting findings suggest that this area requires further investigation.

A further possibility is that some other factor, unrelated to self-relevance, led to differences in episodic specificity for the category and self-related cues. Across a series of experiments, Uzer, Lee and Brown (2012) found that participants demonstrated slower autobiographical retrieval when cued with emotion words compared to object words, consistent with other studies that suggest memories are organised around concrete rather than abstract concepts (e.g. Larsen \& Plunkett, 1987; Robinson, 1976). In the present study, the categories 'journey' and 'another person' were relatively non-emotional, concrete cues. Similarly, the self-image cues used were generally concrete (i.e. specific) in nature (referring to roles or hobbies such as being a husband, a retired mechanic, or a keen gardener). The identity quality measure employed showed that only $11 \%$ (AD group) and 33\% (control group) of self-images were coded as abstract (i.e., traits or emotional states). Thus, it is 
unlikely that the pattern of results was due to differences in the concreteness of the cues used in the two tasks.

These results have important clinical implications as they suggest a new framework for understanding which memories are most resilient in dementia. Dementia charities often explain memory loss to the general public though the bookshelf model of memory storage. This is the idea that, in dementia, the most recent memories (on the highest shelves of the bookcase) are lost first, with those from early adulthood and childhood (on the lowest shelves) persisting the longest. Although there is support in the literature for the resilience of memories from early adulthood compared to the more recent past (e.g. Addis \& Tippett, 2004; Greene et al., 1995; Sagar et al., 1988) the pattern of memory loss in dementia is more complex than a simple temporal gradient. Indeed, whilst Greene et al. (1995) demonstrated a temporal gradient for episodic but not semantic memory, other studies report the opposite finding: a temporal gradient for semantic but not episodic memory (e.g. Addis \& Tippett, 2004; Piolino et al., 2003). The results of the present study suggest that perhaps it is those memories that are most central to the self that persist the longest, rather than memories from early adulthood per se - a pattern that has been proposed previously in healthy adults (Rathbone et al., 2008). This suggestion is supported by data from Fromholt and Larsen (1991) who did not find evidence of selective preservation of memories from early adulthood in dementia, but instead noted that transitional or landmark events tended to be better preserved compared to non-transitional events. Of note, heightened retrieval for events from early adulthood, which is shown very robustly by the 'reminiscence bump' effect (Rubin, Rahaal \& Poon, 1998), may be related to the fact this period consists of many transitional events that are highly self-relevant (Fitzgerald, 1988; Rathbone et al., 2008). Thus, it is possible that many studies showing a relative sparing of early memories in dementia are simply reflecting the preservation of highly self-relevant memories. 
One of the most novel aspects of this study was its attempt to compare the episodic specificity of

self-relevant and less self-relevant autobiographical memories, in essence creating a control condition cue to allow comparison with self-supporting memories. However, it is acknowledged that it is inherently difficult to examine non-self-related (or less-self-related) autobiographical memories - which are all, by definition, self-related. Nevertheless, the experimental design generated a robust effect in three very different groups of participants (AD patients and older adults in the current study, and young adults in Rathbone et al., 2015), suggesting that the cue manipulation was successful at indexing different types of memories. Future studies employing this methodology would benefit from inclusion of a historical events dating task, to elucidate whether temporal organisation is intact for both public and private knowledge and ascertain whether patients' dating is reliable.

Following a systematic review, Caddell and Clare (2011a) stressed the need for evidence-based interventions to support self and identity in dementia, as few studies to date included formal outcome measures (see also Caddell \& Clare,2011b). The present study could be used to guide more structured reminiscence therapy and inform the development of future interventions, as results suggest that identity can be maintained in $A D$ by structuring retrieval around periods that are important to the self. Rather than this being young adulthood per se, the lifetime periods that are most self-relevant will depend on the individual. For some people this might be their marriage and memories of their wedding day. For others it might have been a period in a particular job, living in a new city, or on a certain holiday. Recognising the need for person-centred care (Kitwood, 1997), the most effective interventions are likely to be tailored to the individual and could potentially use 'I am' statements as a starting point for reminiscence work. In this way, therapeutic interventions could involve accessing the memories that are most important for that person. As demonstrated in this study, using self-images to cue memories is unlikely to boost episodic recollection, but it is likely to generate a set of positively valenced semantic memories that may form an important scaffold for identity. 
Whilst using self-images to cue memories is one potential approach for reminiscence therapy, the reverse approach (using memories to cue self-images) may also be of benefit. Activating significant autobiographical memories may strengthen identity, in line with the bidirectional model of self and memory proposed by Conway (2005). For example, in later stages of AD when 'I am' statements cannot be elicited, it might be possible to build on knowledge and memories that are accessible to support identity. Thus, someone repeatedly asking for their husband to visit would demonstrate that the knowledge of being married is still accessible, and that the identity of being a wife is still important to that person. In summary, whilst these findings suggest that the self is maintained in the early stages of $A D$, we suggest that self-based reminiscence could be of benefit in later stages of the disease when cognitive decline poses a greater threat to self-integrity.

It is important to note that the patients sampled were not at an advanced stage of AD (MOCA scores ranged from 12-25, Mean $=17.63)$, a requirement due to the length and relative complexity of some of the tasks used. However, interventions are likely to be more successful at earlier stages of disease progression when there is less brain atrophy, more cognitive ability and fewer behavioural changes. Apathy and mood disorder more commonly found in later stages of AD (Nobis \& Husain, 2018) would likely impact on the effectiveness of interventions. On the other hand, as Clare et al. (2013) suggest, it may be in the later stages of dementia that interventions based on supporting self concept will have the largest benefits for improving quality of life. Thus, whilst these findings are relevant to this stage of $A D$, future work should explore parallel but adapted methods in later stages of disease progression.

\subsection{Conclusions}

To conclude, we found that the self in $A D$ is relatively intact and equivalent to that of healthy older adults. Although fewer self-images and self-supporting memories were generated by the AD group, they exhibited similar self-related clustering to controls, supporting a coherent life narrative and scaffolding self-knowledge. In both AD and healthy older adults, self-images cued less episodic 
memories compared to a control task cue, which lends further support to the idea that semantic autobiographical memories play a fundamental role in supporting the self. This work suggests that memory loss and cognitive decline do not necessarily lead to lower levels of well-being or less positive views of the self - in fact, our AD patients rated their self-supporting memories more positively than controls. In spite of pronounced autobiographical memory deficits and general cognitive decline, identity can be supported by a small number of factual memories that provide a scaffold for the self. These self-supporting memories may be particularly resistant to the effects of $A D$ and could provide tools for more structured forms of reminiscence therapy. 
Acknowledgements:

This work was supported by an Economic and Social Research Council (ES/K000918/1) grant awarded to Clare J Rathbone. Chris J A Moulin is supported by the Institut Universitaire de France, Samrah Ahmed is supported by Alzheimer's Research UK, and Christopher R Butler is supported by a Medical Research Council Clinician Scientist Fellowship (MR/K010395/1). Thank you to Sarah Smith and colleagues at the University of Bradford School of Dementia Studies for helpful discussions around $A M$ and identity in AD. 


\section{References}

Addis, D. R., \& Tippett, L. J. (2004). Memory of myself: autobiographical memory and identity in Alzheimer's disease. Memory, 12(1), 56-74.

Addis, D. R., \& Tippett, L. J. (2008). The contributions of autobiographical memory to the content and continuity of self: a social-cognitive neuroscience approach. In F. Sani (Ed.), Self-Continuity: Individual and Collective Perspectives (pp. 71-84). New York: Psychology Press.

Ahmed, S., de Jager, C., \& Wilcock, G. (2011). A comparison of screening tools for the assessment of mild cognitive impairment: preliminary findings. Neurocase, 18(4), 336-351.

Ahmed, S., Irish, M., Loane, C., Baker, I., Husain, M., Thompson, S., Blanco-Duque, C., Mackay, C., Zamboni, G., Foxe, D., Hodges, J.R., Piguet, O., \& Butler, C. (2018). Association between precuneus volume and autobiographical memory impairment in posterior cortical atrophy: Beyond the visual syndrome. Neuroimage Clinical, 18, 822-834.

Baddeley, A. D., \& Wilson, B. (1986). Amnesia, autobiographical memory and confabulation. In D. C. Rubin (Ed.), Autobiographical Memory (pp. 225-52). Cambridge: Cambridge University Press.

Bennouna-Greene, M., Berna, F., Conway, M. A., Rathbone, C. J., Vidailhet, P., \& Danion, J. M. (2012). Selfimages and related autobiographical memories in schizophrenia. Consciousness and Cognition, 21, 247-257.

Berntsen, D. (2009). Involuntary autobiographical memories. An introduction to the unbidden past. Cambridge, England: Cambridge University Press.

Caddell, L. S., \& Clare, L. (2010). The impact of dementia on self and identity: A systematic review. Clinical Psychology Review, 30(1), 113-126.

Caddell, L. S., \& Clare, L. (2011a). Interventions supporting self and identity in people with dementia: A systematic review. Aging \& Mental Health, 15(7), 797-810.

Caddell, L. S., \& Clare, L. (2013a). A profile of identity in early-stage dementia and a comparison with healthy older people. Aging \& Mental Health, 17(3), 319-27. 
Caddell, L. S., \& Clare, L. (2011b) Studying the self in people with dementia: How might we proceed?

Dementia-International Journal of Social Research and Practice, 12(2), 192-209.

Caddell, L. S., \& Clare, L. (2013b). How does identity relate to cognition and functional abilities in early-stage dementia? Aging Neuropsychology and Cognition, 20(1), 1-21.

Carson, N., Leach, L., \& Murphy, K.J. (2018). A re-examination of Montreal Cognitive Assessment (MoCA) cutoff scores. International Journal of Geriatric Psychiatry, 33(2), 379-388.

Chessel, Z., Rathbone, C.J., Souchay, C., Charlesworth, L., Moulin, C.J.A. (2014). Autobiographical Memory, Past and Future Events and Self-images in Younger and Older Adults. Self and Identity, 13(4), 380397.

Chiti, G., \& Pantoni, L. (2014). Use of Montreal cognitive assessment in patients with stroke. Stroke, 45, $3135-3140$.

Clare, L., Whitaker, C. J., Nelis, S. M., Martyr, A., Markova, I. S., Roth, I., et al. (2013). Self-concept in early stage dementia: profile, course, correlates, predictors and implications for quality of life. International Journal of Geriatric Psychiatry, 28(5), 494-503.

Conway, M.A. (2005). Memory and the self. Journal of Memory and Language, 53(4), 594-628.

Conway, M.A. \& Plydell-Pearce, C.W. (2000). The construction of autobiographical memories in the self memory system. Psychological Review, 107, 261-288.

Conway M.A., Singer J.A., \& Tagini A. (2004). The self and autobiographical memory: Correspondence and coherence. Social Cognition, 22(5), 491-529.

Diener, E., Emmons, R., Larsen, J., \& Griffin, S. (1985). The satisfaction with life scale. Journal of Personality Assessment, 49(1), 71-75.

El Haj, M., \& Antoine, P. (2017). Describe yourself to improve your autobiographical memory: A study in Alzheimer's disease. Cortex, 88, 165-172.

El Haj, M., Fasotti, L.,\& Allain, P. (2012). The involuntary nature of music-evoked autobiographical memories in Alzheimer's disease. Consciousness \& Cognition, 21(1), 238-46. 

1

El Haj, M., Antoine, P., Nandrino, J. L., \& Kapogiannis, D. (2015). Autobiographical memory decline in Alzheimer's disease, a theoretical and clinical overview. Ageing Research Reviews, 23(Pt B), 183-92.

Ernst, A., Gourisse, L., Wauquiez, G. \& Souchay, C. (2016) Autobiographical memory and the self in a singlecase of chronic unilateral spatial neglect. Neurocase, 22(3), 276-280.

Eustache, M. L., Laisney, M., Juskenaite, A., Letortu, O., Platel, H., Eustache, F., et al. (2013). Sense of identity in advanced Alzheimer's dementia: a cognitive dissociation between sameness and selfhood? Consciousness \& Cognition, 22(4), 1456-1467.

Fargeau, M. N., Jaafari, N., Ragot, S., Houeto, J. L., Pluchon, C., \& Gil, R. (2010). Alzheimer's disease and impairment of the Self. Consciousness \& Cognition, 19(4), 969-976.

Fitzgerald, J.M. (1988). Vivid memories and the reminiscence phenomenon: The role of a self narrative. Human Development, 31, 261-273.

Fotopoulou, A., Conway, M. A., Griffiths, P., Birchall, D., \& Tyrer, S. (2007). Self-enhancing confabulation: revisiting the motivational hypothesis. Neurocase, 13(1), 6-15.

Fromholt, P., \& Larsen, S.F. (1991). Autobiographical memory in normal aging and primary degenerative dementia (dementia of Alzheimer type). Journal of Gerontology, 46(3), 85-91.

Gardiner, J. M. (1988). Functional aspects of recollective experience. Memory \& Cognition, 16, 309-313.

Genon, S., Bahri, M. A., Collette, F., Angel, L., d'Argembeau, A., Clarys, D., et al. (2014). Cognitive and neuroimaging evidence of impaired interaction between self and memory in Alzheimer's disease. Cortex, 51, 11-24

Greene, J. D., Hodges, J. R., \& Baddeley, A. (1995). Autobiographical memory and executive function in early dementia of Alzheimer type. Neuropsychologia, 33(12), 1647-70.

Grilli, M. D. (2017). The association of personal semantic memory to identity representations: Insight into higher-order networks of autobiographical contents. Memory, 25,1435-1443.

Grilli, M. D., \& Verfaellie, M. (2015). Supporting the self-concept with memory: insight from amnesia. Social Cognitive and Affective Neuroscience, 10(12), 1684-1692. 
Harrison, B. E., Therrien, B. A., \& Giordani, B. J. (2005). Alzheimer's disease behaviors from past selfidentities: an exploration of the memory and cognitive features. American journal of Alzheimer's disease and other dementias, 20(4), 248-254.

Haslam, C., Jetten, J., Haslam, S. A., Pugliese, C., \& Tonks, J. (2011). 'I remember therefore I am, and I am therefore I remember': Exploring the contributions of episodic and semantic self-knowledge to strength of identity. British Journal of Psychology, 102, 184-203.

Hehman, J. A., German, T. P., Klein, S. B. (2005). Impaired Self-Recognition from Recent Photographs in a Case of Late-Stage Alzheimer's Disease. Social Cognition, 23, 118-124.

Irish, M., Addis, D. R., Hodges, J. R., \& Piguet, O. (2012) Considering the role of semantic memory in episodic future thinking: evidence from semantic dementia. Brain, 135, 2178-2191.

Kitwood, T. M., (1997). Dementia reconsidered: The person comes first. Buckingham, England: Open University Press.

Klein, S. B. (2012). The Self and Science: Is It Time for a New Approach to the Study of Human Experience? Current Directions in Psychological Science, 21(4), 253-257.

Klein, S. B., Cosmides, L., \& Costabile, K. A. (2003). Preserved Knowledge of Self in a Case of Alzheimer's Dementia. Social Cognition, 21(2), 157-165.

Klein, S. B., \& Gangi, C. E. (2010). The multiplicity of self: neuropsychological evidence and its implications for the self as a construct in psychological research. In A. Kingstone \& M. B. Miller (Eds.), Year in Cognitive Neuroscience 2010 (Vol. 1191, pp. 1-15). Malden: Wiley-Blackwell.

Klein, S. B., Rozendal, K., \& Cosmides, L. (2002). A social-cognitive neuroscience analysis of the self. Social Cognition, 20(2), 105-135.

Kopelman, M. D., Wilson, B. A., \& Baddeley, A. D. (1989). The autobiographical memory interview - a new assessment of autobiographical and personal semantic memory in amnesic patients. Journal of Clinical and Experimental Neuropsychology, 11(5), 724-744.

Locke, J. (1694/1975). An essay concerning human understanding. In J. Perry (Ed.), Personal Identity. Berkeley: University of California Press. 
Larsen, S. F., \& Plunkett, K. (1987). Remembering experienced and reported events. Applied Cognitive Psychology, 1(1), 15-26.

Levine, B., Svoboda, E., Hay, J. F., \& Winocur, G. (2002). Aging and autobiographical memory: Dissociating episodic from semantic retrieval. Psychology and Aging, 17(4), 677-689.

Martinelli, P., Anssens, A., Sperduti, M., \& Piolino, P. (2013). The influence of normal aging and Alzheimer's disease in autobiographical memory highly related to the self. Neuropsychology, 27(1), 69-78.

McKenna, P., \& Warrington, E. K. (1983). The Graded Naming Test. Windsor, Berks: NFER-Nelson.

McKhann, G. M., Knopman, D. S., Chertkow, H., Hyman, B. T., Jack, C. R., Kawas, C. H., ... Phelps, C. H. (2011). The diagnosis of dementia due to Alzheimer's disease: Recommendations from the National Institute on Aging-Alzheimer's Association workgroups on diagnostic guidelines for Alzheimer's disease.

Alzheimer's \& Dementia : The Journal of the Alzheimer's Association, 7(3), 263-269.

Miles, A. N., Fischer-Mogensen, L., Nielsen, N. H., Hermansen, S., \& Berntsen, D. (2013). Turning back the hands of time: Autobiographical memories in dementia cued by a museum setting. Consciousness \& Cognition, 22(3), 1074-1081.

Mograbi, D. C., Brown, R. G., \& Morris, R. G. (2009). Anosognosia in Alzheimer's disease - The petrified self. Consciousness and Cognition, 18(4), 989-1003.

Morris, R. G., \& Mograbi, D. C. (2013). Anosognosia, autobiographical memory and self knowledge in Alzheimer's disease. Cortex, 49(6), 1553-1565.

Nobis, L. \& Husain, M. (2018). Apathy in Alzheimer's disease. Current Opinion in Behavioral Sciences, 22, 713.

Osterrieth, P. A. (1944). Le test de copie d'une figure complexe. Archives de Psychologie, 30, 206-356.

Piolino, P., Desgranges, B., Belliard, S., Matuszewski, V., Lalevee, C., De La Sayette, V., et al. (2003).

Autobiographical memory and autonoetic consciousness: triple dissociation in neurodegenerative diseases. Brain, 126, 2203-2219.

Piolino, P., Desgranges, B., \& Eustache, F. (2009). Episodic autobiographical memories over the course of time: cognitive, neuropsychological and neuroimaging findings. Neuropsychologia, 47(11), 2314-29. 
Piolino, P., Desgranges, B., \& Eustache, F. (2000). La mémoire autobiographique: Théorie et pratique. Marseille, France: Solal.

Prebble, S. C., Addis, D. R., \& Tippett, L. J. (2013). Autobiographical memory and sense of self. Psychological Bulletin, 139(4), 815-40.

Rankin, K. P., Baldwin, E., Pace-Savitsky, C., Kramer J. H., \& Miller, B.L. (2005). Self awareness and personality change in dementia. Journal of Neurology, Neurosurgery and Psychiatry, 76(5), 632-639.

Rathbone, Clare (2015). Memory and the self in ageing. [Data Collection]. Colchester, Essex: UK Data Archive. $\underline{10.5255 / \text { UKDA-SN-852127 }}$

Rathbone, C.J., Conway, M.A., \& Moulin, C.J.A. (2011). Remembering and imagining: the role of the self. Consciousness \& Cognition, 20(4), 1175-1182.

Rathbone, C.J., Holmes, E.A., Murphy, S.E. \& Ellis, J.A., (2015). Autobiographical memory and well-being in aging: the central role of semantic self-images Consciousness \& Cognition, 33, 422-431.

Rathbone, C.J., Moulin, C.J.A., \& Conway, M.A. (2009). Autobiographical memory and amnesia: using conceptual knowledge to ground the self. Neurocase, 15(5), 405-418.

Rathbone, C.J., Moulin, C.J.A., \& Conway, M.A. (2008). Self-Centred Memories: the Reminiscence bump and the Self. Memory \& Cognition, 36(8), 1403-14.

Reisberg, D., Pearson, D. G. and Kosslyn, S. M. (2003). Intuitions and introspections about imagery: the role of imagery experience in shaping an investigator's theoretical views. Applied Cognitive Psychology, $17,147-160$.

Reitan, R. M. (1958). Validity of the Trail Making Test as an indicator of organic brain damage. Perceptual and Motor Skills, 8, 271-276.

Renoult, L., Davidson, P.S.R., Palombo, D.J., Moscovitch, M., \& Levine, B. (2012). Personal Semantics: At the crossroads of semantic and episodic memory. Trends in Cognitive Sciences, 16(11), 550-558.

Renoult, L., Tanguay, A., Beaudry, M., Tavakoli, P., Moscovitch, M., Levine, B., Campbell, K., \& Davidson, P.S.R. (2016) Personal semantics: Is it distinct from episodic and semantic memory? An 
electrophysiological study of memory for repeated events and autobiographical facts.

Neuropsychologia, 83, 242-256.

Rey, A. (1941). L'examen psychologie dan les cas d'encephalopathie traumatique (Les problemes). Archives de Psychologie, 28, 286-340.

Rhee. E., Uleman, J. S., Lee, H. K., \& Roman, R .J. (1995). Spontaneous self descriptions and ethnic identities in individualist and collective cultures. Journal of Personality and Social Psychology, 69, 142-152.

Robinson, J. A. (1976). Sampling autobiographical memory. Cognitive Psychology, 8(4), 578-595.

Rogers, T. B., Kuiper, N. A., \& Kirker, W. S. (1977). Self-reference and the encoding of personal information. Journal of Personality and Social Psychology, 35(9), 677-688.

Rubin, D.C., Rahaal, T.A. and Poon, L.W. (1998). Things learned in early adulthood are remembered best. Memory and Cognition, 26(1), 3-19.

Sagar, H. J., Cohen, N. J., Sullivan, E. V., Corkin, S., \& Growdon, J.H. (1988). Remote memory function in Alzheimer's disease and Parkinson's disease. Brain, 111(1), 185-206.

Scheier, M. F., Carver, C. S., \& Bridges, M. W. (1994). Distinguishing optimism from neuroticism (and trait anxiety, self-mastery, and self-esteem): A re-evaluation of the Life Orientation Test. Journal of Personality and Social Psychology, 67, 1063-1078.

Seidl, U., Lueken, U., Thomann, P. A., Geider, J., \& Schröder, J. (2011). Autobiographical memory deficits in Alzheimer's disease. Journal of Alzheimers Disease, 27(3), 567-74.

Singer, J.A., and Salovey, P. (1993). The Remembered Self. New York: The Free Press.

Strohminger, N. \& Nichols, S. (2015). Neurodegeneration and Identity. Psychological Science, 26(9), 14691479.

Sunderland, A., Harris, J. E., \& Gleave, J. (1984). Memory failures in everyday life following severe head injury. Journal of Clinical Neuropsychology, 6(2), 127-142.

Thomsen, D. K. (2009). There is more to life stories than memories. Memory, 17(4), 445-457.

Thomsen, D. K. \& Berntsen, D. (2005). The end point effect in autobiographical memory: More than a calendar is needed, Memory, 13(8), 846-861. 
Thomsen, D. K., Pillemer, D. B., \& Ivcevic, Z. (2011). Life story chapters, specific memories and the reminiscence bump. Memory, 19(3), 267-279.

Tippett, L. J., Prebble, S. C., \& Addis, D. R. (2018). The Persistence of the Self over Time in Mild Cognitive Impairment and Alzheimer's Disease. Frontiers in Psychology, 9, 94.

Tombaugh, T. N., Kozak, J., \& Rees, L. (1999). Normative data stratified by age and education for two measures of verbal fluency: FAS and animal naming. Archives of Clinical Neuropsychology, 14(2), 167-177.

Tulving, E. (1985). How many memory systems are there? American Psychologist, 40, 385-398.

Uzer, T., Lee, P. J., \& Brown, N. R. (2012). On the prevalence of directly retrieved autobiographical memories. Journal of Experimental Psychology: Learning, Memory, and Cognition, 38(5), 1296-1308.

Watson, D., Clark, L. A., \& Tellegen, A. (1988). Development and validation of brief measures of positive and negative affect: The PANAS scales. Journal of Personality and Social Psychology, 54(6), 1063-1070.

Wechsler, D. (1981) Manual for the Wechsler Adult Intelligence Scale-Revised. New York: Psychological Corporation.

Wechsler, D. (1997). Wechsler Memory Scale-Third Edition manual. San Antonio, TX: The Psychological Corporation.

World Health Organization. (2017, December 12). Dementa. Retrieved from http://www.who.int/en/newsroom/fact-sheets/detail/dementia

Wong, S., Irish, M., Leshikar, E.D., Duarte, A., Bertoux, M., Savage, G., Hodges, J.R., Piguet, O., \& Hornberger, M. (2017). The self-reference effect in dementia: Differential involvement of cortical midline structures in Alzheimer's disease and behavioural-variant frontotemporal dementia. Cortex, 91, 169185.

Zigmond, A. S., \& Snaith, R. P. (1983). The hospital anxiety and depression scale. Acta Psychiatrica Scandinavica, 67(6), 361-370. 


\section{Supplementary materials: younger adult results for self and category-cued memories}

32 younger adults (Mean age $=20.25, S D=2.99$; full participant information reported in Rathbone et al., 2015) completed the same memory tasks as the older adult and AD groups, generating episodic specificity and proportion JR scores for self-cued and category-cued memories. Mean scores are shown in Fig. 1 below.
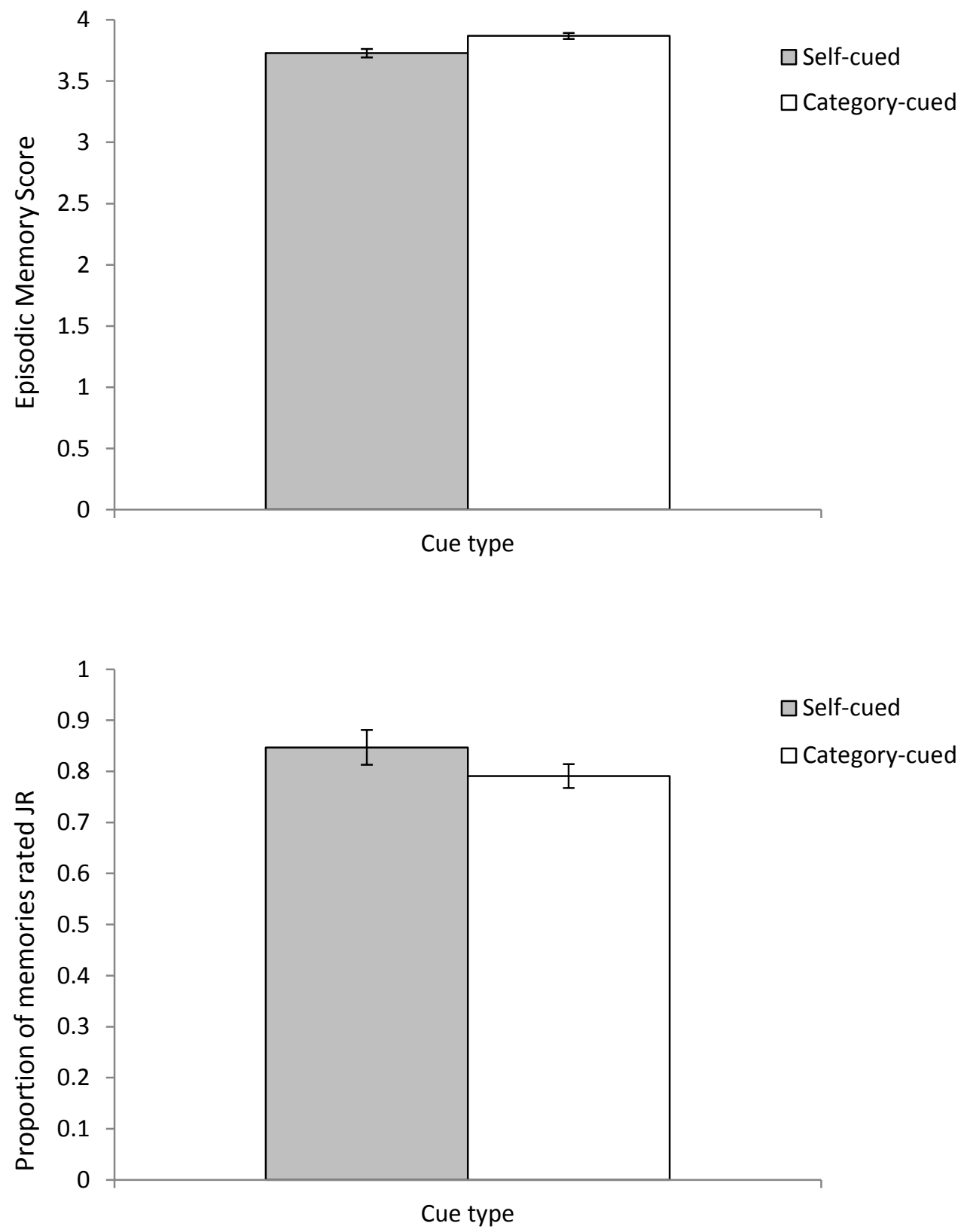

Supplementary Fig. 1: Mean episodic specificity scores (upper panel) and proportion JR scores (lower panel) for younger adults according to type of memory cue (error bars show standard error)

Younger adults' category-cued memories had significantly higher episodic specificity scores compared to self-cued memories $(t(31)=-2.78, p=.009, r=.45)$. There was no significant difference between proportion JR scores for category-cued and self-cued memories $(t(31)=1.74, p=.092)$. 


\begin{abstract}
'The prediction that AD patients would generate more abstract (rather than specific) self-images is based on the broader finding that $A D$ patients tend to generate information that is less concrete and more vague in general (e.g. lower episodic memory specificity), potentially due to deficits in lexical access (Mograbi \& Morris, 2013).
\end{abstract}

ii In accordance with Cortex TOP requirements, all individual anonymised data (at raw and summary level) that are necessary and sufficient to reproduce all analyses and data presentations in the manuscript and supplementary materials are available online (Rathbone, 2015) at: http://reshare.ukdataservice.ac.uk/852127/ Collections B and C contain all data along with digital materials (e.g. the IAM and Category Tasks). The standardised measures used to collect scores on the mood and well-being scales and cognitive tasks have not been uploaded as these are copyright protected. These standardised measures are fully referenced in this manuscript and copyright holders can be contacted to gain access.

iii Seventeen AD patients were recruited in total but one was excluded from the analysis as he was unable to generate any memories in the IAM Task.

iv The 29 control participants were a sub-set of the 32 participants reported in Rathbone et al (2015) who had MOCA scores of $\geq 25$. Rathbone et al (2015) focused on correlations between measures of well-being and positivity ratings for self-images and self-image cued memories. The analysis of self-supporting memory distributions and all category-cued memory data is entirely novel to this paper. Sample sizes were determined based on previous similar studies (e.g. Eustache et al., 2013; Martinelli et al., 2013).

${ }^{\vee}$ The control group also completed the Spontaneous Use of Imagery Scale (SUIS; Reisberg, Pearson \& Kosslyn, 2003), Trail Making Tests A and B (Reitan, 1958), and dichotomously rated memories as observer or field. The SUIS task and Trail Making Tests were not used with the AD group, nor were they required to rate memories as observer or field. Consequently, results from the SUIS, Trail Making Tests and observer/field ratings for controls are not presented.

vi The data presented in Tables 2 and 3 were also analysed using non-parametric Mann Whitney $U$ tests, due to differences in sample sizes and the use of Likert scales. An almost identical pattern of results was obtained using these non-parametric equivalent tests, the exception being a significant group difference in ratings of self-image emotional valence with the $A D$ group rating self-images as significantly more positive than controls $(p=.007)$.

vii There were a number of other significant pairwise comparisons but for conciseness these are not reported here.

viii As a significantly higher proportion of the AD group's self-images were rated as concrete compared to controls (see 'Identity Quality' in Table 2), and as previous research has shown that concrete self-images tend to elicit more tightly clustered memory distributions (Rathbone et al., 2008), we examined whether differences in self-image cue types between groups had any impact on the distributions of memories in Figure 1. The frequencies of memories cued by concrete self-images only (i.e. excluding memories cued by abstract self-images) were analysed using a mixed (bin $\mathrm{x}$ group) ANOVA. There was a significant effect of bin $(F(9,387)$ $=12.32, p<.001$, partial $\left.\eta^{2}=.22\right)$ and no group $\mathrm{x}$ bin interaction $(\mathrm{F}<1)$. Again, Bonferroni-corrected pairwise comparisons showed that the bin of central interest, -4 to +5 years around self-emergence, was associated with a significantly higher frequency of memories compared to seven of the nine other bins. In contrast to the analysis on the whole dataset, there was no main effect of group when abstract self-image cued memories were removed $(F<1)$. 